Audiology

Neurotology
Audiol Neurotol 2017;22:356-363

DOI: $10.1159 / 000488386$
Received: October 23, 2017

Accepted: March 12, 2018

Published online: May 2, 2018

\title{
Predicting Sequential Cochlear Implantation Performance: A Systematic Review
}

\author{
Yvette Smulders $^{\mathrm{a}-\mathrm{d}}$ Thomas Hendriks ${ }^{\mathrm{b}, \mathrm{c}}$ Robert Eikelboom ${ }^{\mathrm{a}, \mathrm{c}, \mathrm{e}}$ \\ Inge Stegeman ${ }^{f}$ Peter Santa Maria ${ }^{a-c, g}$ Marcus Atlas ${ }^{a, c}$ Peter Friedland ${ }^{a-c, ~ h ~}$

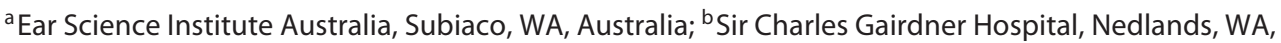 \\ Australia; ' Ear Sciences Centre, The University of Western Australia, Nedlands, WA, Australia; ${ }^{\mathrm{d} D e p a r t m e n t}$ of \\ Otorhinolaryngology, Rivas Zorggroep, Gorinchem, The Netherlands; ${ }^{\text {eDepartment }}$ of Speech-Language Pathology \\ and Audiology, University of Pretoria, Pretoria, South Africa; ${ }^{\mathrm{f} D e p a r t m e n t ~ o f ~ O t o r h i n o l a r y n g o l o g y, ~ H e a d ~ a n d ~ N e c k ~}$ \\ Surgery, University Medical Centre Utrecht, Utrecht, The Netherlands; ${ }^{9}$ Department of Otolaryngology, Head and \\ Neck Surgery, Stanford University, Stanford, CA, USA; h School of Medicine, University of Notre Dame, \\ Fremantle, WA, Australia
}

\section{Keywords}

Predict · Sequential · Bilateral · Cochlear implantation ·

Adult $\cdot$ Hearing loss

\begin{abstract}
This systematic review of the literature reveals which preoperative factors affect sequential cochlear implantation outcomes in adults. The findings can help health care professionals provide evidence-based advice on the expected benefits from a second cochlear implant $(\mathrm{Cl})$. We searched PubMed, EMBASE, and the Cochrane database from November 1977 to August 26, 2017, using the terms "sequential cochlear implantation"; the most frequently cited predictors for unilateral cochlear implantation performance and other potential predictors for sequential implantation outcome; and "speech perception," "localization" as well as synonyms of all of the above. Ten studies were included. The effects of age, duration of hearing loss, time between implantations, preoperative hearing, etiology of hearing loss, hearing aid use and duration of follow-up on sequential cochlear im-
\end{abstract}

\section{KARGER}

(c) 2018 S. Karger AG, Basel

E-Mail karger@karger.com

www.karger.com/aud plantation performance were studied. The literature has shown that duration of deafness, age at onset of deafness, etiology of hearing loss, and preoperative speech perception score are (inversely) related to unilateral cochlear implantation outcome in adults. One would expect that these factors would also affect sequential bilateral implantation outcome. However, the best available evidence to date shows that advanced age, a long duration of deafness, or a long interval between implantations should not be considered negative factors when considering sequential bilateral cochlear implantation.

(c) 2018 S. Karger AG, Basel

\section{Introduction}

Bilateral cochlear implantation is becoming a common treatment for bilateral hearing loss in a growing number of countries. It is widely recognized that bilateral implantation provides important hearing benefits including enhanced sound localization, greater speech-in-noise un- 


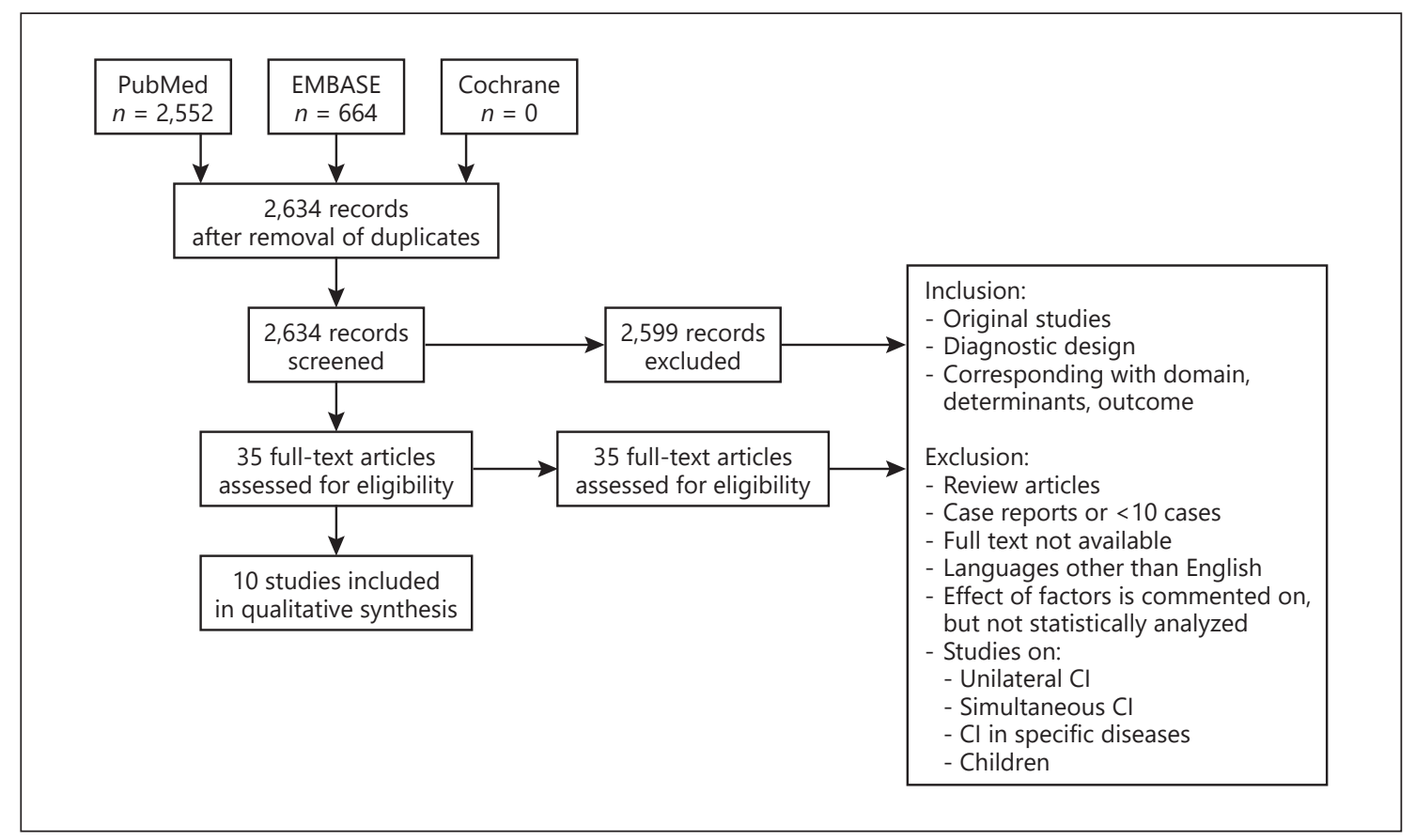

Fig. 1. Article selection process according to the PRISMA guidelines.

derstanding, and an improved quality of life [Dunn et al., 2012; Laszig et al., 2004; Litovsky et al., 2006; Müller et al., 2002; Nopp et al., 2004; Tyler et al., 2007; Verschuur et al., 2005]. Bilateral cochlear implantation enables use of the head shadow, loudness summation, and binaural squelch effects [Kraaijenga et al., 2016; Van Deun et al., 2010]. Cochlear implant (CI) teams often make cost-benefit decisions of the sequential implant based on the literature, which is primarily focused on unilateral cochlear implantation. This shows that duration of deafness, age at onset of deafness, etiology of hearing loss, and preoperative speech perception score are (inversely) related to unilateral cochlear implantation outcome [Blamey et al., 2013; Friedland et al., 2010; Green et al., 2007; Holden et al., 2013; Leung et al., 2005; Rubinstein et al., 1999]. With the increasing demand for bilateral cochlear implantation, it would be useful if we could predict the level of benefit from a second CI. This would improve preoperative counseling, allow early identification of slow progress after implantation and ultimately ensure that patients who will benefit will receive a second CI. The goal of this systematic review of the literature is to analyze which preoperative factors affect outcomes, as defined by speech recognition and localization after sequential bilateral cochlear implantation according to the best available evidence to date.

\section{Methods}

\section{Search Strategy}

In conducting this systematic review, we followed the PRISMA guidelines [Moher et al., 2009]. To identify studies that assessed the factors that have an influence on cochlear implantation outcome, we searched PubMed, EMBASE, and the Cochrane database from November 1977 to August 2017, using the terms "sequential cochlear implantation" and its synonyms as the domain; the most frequently cited predictors for unilateral cochlear implantation performance, other potential predictors for sequential implantation outcome, and their synonyms as the determinants; and "speech perception or localization" and their synonyms as the outcome. The exact search strategy was: Cochlear implant* AND (sequent* OR bilateral OR second*) AND (predict* OR factor OR characteristic* OR variable* OR aetiol* OR etiol* OR age OR hearing preserv* OR hearing loss OR hearing depriv* OR duration of deaf* OR duration of hearing loss OR cause of deaf* OR speech intel* OR speech percept* OR hearing aid OR amplificat* OR gender OR comorbid* OR general health* OR delay OR inter implant* OR time OR interval) AND (speech* OR sound perception OR hearing OR listening OR in noise OR performance OR localis* OR localiz* OR lateralis* OR lateralize* OR speech). In addition, the titles and abstracts of the references of the relevant papers and related articles were screened (Fig. 1).

\section{Study Selection}

The first two named authors of this review independently screened all identified titles and abstracts. Potentially relevant studies were obtained and the full texts were obtained and read. 
Table 1. Relevance and risk of bias

\begin{tabular}{|c|c|c|c|c|c|c|c|c|c|c|}
\hline \multirow[t]{2}{*}{ Study } & \multirow{2}{*}{$\begin{array}{l}\text { Study } \\
\text { design }\end{array}$} & \multicolumn{3}{|c|}{ Relevance $^{1}$} & \multicolumn{6}{|c|}{ Risk of bias ${ }^{2}$} \\
\hline & & domain & $\begin{array}{l}\text { deter- } \\
\text { minant }\end{array}$ & $\begin{array}{l}\text { out- } \\
\text { come }\end{array}$ & $\begin{array}{l}\text { study } \\
\text { partici- } \\
\text { pation }\end{array}$ & $\begin{array}{l}\text { study } \\
\text { attrition }\end{array}$ & $\begin{array}{l}\text { PF } \\
\text { measure- } \\
\text { ment }\end{array}$ & $\begin{array}{l}\text { outcome } \\
\text { measure- } \\
\text { ment }\end{array}$ & $\begin{array}{l}\text { study con- } \\
\text { founding }\end{array}$ & $\begin{array}{l}\text { statistical } \\
\text { analysis and } \\
\text { reporting }\end{array}$ \\
\hline Nopp et al., 2004 & cohort & + & + & + & - & + & - & + & - & $+/-$ \\
\hline Schleich et al., 2004 & cohort & + & + & + & - & + & - & + & - & - \\
\hline Ramsden et al., 2005 & cohort & + & + & + & $+/-$ & $+/-$ & - & + & - & - \\
\hline Zeitler et al., 2008 & cohort & + & + & + & + & $+/-$ & $+/-$ & + & - & + \\
\hline Laske et al., 2009 & cohort & + & + & + & + & - & $+/-$ & + & - & + \\
\hline Dorman et al., 2012 & cohort & $+/-$ & + & + & - & - & $+/-$ & + & - & $+/-$ \\
\hline Boisvert et al., 2012 & cohort & + & + & + & + & + & + & + & $+/-$ & + \\
\hline Reeder et al., 2014 & cohort & + & + & + & + & $+/-$ & $+/-$ & + & $+/-$ & + \\
\hline Boisvert et al., 2016 & cohort & + & + & + & $+/-$ & $+/-$ & $+/-$ & + & $+/-$ & + \\
\hline Ohta et al., 2017 & cohort & + & + & + & $+/-$ & - & $+/-$ & + & - & $+/-$ \\
\hline
\end{tabular}

${ }^{1}$ Domain: the patients included were adults who underwent sequential cochlear implantation. Determinant: the study describes predictive factors for performance with bilateral cochlear implants or performance with a second implant. Outcome: either speech understanding (in silence or noise) or localization. Relevant $(+)$ and article is relevant but the main focus was on a different group of patients $(+/-)$.

${ }^{2}$ Study participation: the sample represents the population of interest on key characteristics, sufficient to limit potential bias of the observed relationship between predictive factor and outcome. Study attrition: loss to follow-up (from baseline sample to study population analyzed) is not associated with key characteristics (i.e., the study data adequately represent the sample) sufficient to limit potential bias to the observed relationship between prognostic factor and outcome. Prognostic factor (PF) measurement: $\mathrm{PF}$ is adequately measured in study participants to sufficiently limit potential bias. Outcome measurement: outcome of interest is adequately measured in study participants to sufficiently limit potential bias. Study confounding: important potential confounders are appropriately accounted for, limiting potential bias with respect to the relationship between PF and outcome. Statistical analysis and reporting: appropriate for the design of the study, limiting the potential for presentation of invalid or spurious results. A low risk of bias (+), a moderate risk of bias $(+/-)$, and a high risk of bias (-) according to a summary of the QUIPS tool for assessment of bias [Hayden et. al., 2013].

Criteria for inclusion and exclusion are shown in Figure 1. The relevance of studies was assessed by the same two researchers. We considered a study relevant when it conveyed the results of adult patients undergoing sequential cochlear implantation (domain), potential factors influencing the outcome (determinants) and when the outcome measure was either hearing, speech recognition, and/or sound localization (outcome) (Table 1). Subsequently, we assessed the chance of bias in each study. We used an approach based on the QUIPS tool [Hayden et al., 2013]. This is appropriate for prognostic factor review questions and has been recommended by the Cochrane Prognosis Methods Group. We assessed the risk of bias concerning 6 domains: study participation, study attrition, prognostic factor measurement, outcome measurement, study confounding, and statistical analysis and reporting (Table 1).

\section{Data Extraction}

From each study, we extracted the age at test, duration of deafness at test, duration of bilateral cochlear implant use, time interval between sequential implantations, and which outcome measures were used. Due to heterogeneity in the presentation of results from individual studies, we extracted information from graphs or directly calculated the results from data presented in tables when not originally reported. When we performed this, we indicated it with an asterisk. Due to large heterogeneity between the studies included, pooling of data was not possible. We therefore summarized the outcomes per study (Table 2).

\section{Results}

Our initial search generated a total of 3,216 possible relevant titles. After the removal of duplicates, 2,634 titles remained. Titles, abstracts, and full-text articles were consecutively screened for the inclusion and exclusion criteria (Fig. 1). Ten papers were included in this systematic review. The quality of the papers is summarized in Table 1. In most studies, the data were gathered retrospectively. Randomization did not take place in any of the studies.

Table 1 provides a summary of the study designs and quality assessment of the reviewed studies. All included studies were cohort studies. In order to be included in this systematic review, the domain, determinant, and outcome had to be relevant. The study of Dorman et al. [2012] included both bilaterally implanted patients and bimodal patients (wearing a CI and a hearing aid). The right 6 columns summarize the various risks of bias. They are further explained in the table footnote.

Table 2 shows the study characteristics of each study. It also indicates the total numbers of participants included in each study and performing the various tests. In the 
Table 2. Study characteristics

\begin{tabular}{|c|c|c|c|c|c|c|}
\hline Study & $N$ & $\begin{array}{l}\text { Age at the test, } \\
\text { years }\end{array}$ & $\begin{array}{l}\text { DOD at the test, } \\
\text { years }\end{array}$ & $\begin{array}{l}\text { Duration of } \\
\text { bilateral } \\
\text { CI use }\end{array}$ & $\begin{array}{l}\text { Interval between } \\
\text { implantation of } \\
\text { CI1 and CI2, years }\end{array}$ & Test outcome \\
\hline $\begin{array}{l}\text { Schleich et al., } \\
2004\end{array}$ & 21 & $44[17.5-66.5]$ & $12.9[0.6-47.8]$ & $>1$ month & $2.23[0-5.67]$ & OST in noise $(n=21)$ \\
\hline $\begin{array}{l}\text { Zeitler et al., } \\
2008\end{array}$ & 22 & 46.9 & $32.1[3-58.3]$ & 3 months & $5.6[0.5-10]$ & $\begin{array}{l}\text { CNC words in quiet }(n=19) \\
\text { HINT and in quiet }(n=19)\end{array}$ \\
\hline $\begin{array}{l}\text { Laske et al., } \\
2009\end{array}$ & 29 & $\begin{array}{l}31(16) \\
\text { (age at CI1) }\end{array}$ & $5.4^{\mathrm{a}}(6.4)$ & $>6$ months & $5.6(5.7)[0-19]$ & $\begin{array}{l}\text { OST in quiet }(n=23) \text { and in noise }(n=16) \\
\text { Localization }(n=?)\end{array}$ \\
\hline $\begin{array}{l}\text { Boisvert et al., } \\
2012\end{array}$ & 10 & $\begin{array}{l}61[37-88] \\
\text { (age at CI2) }\end{array}$ & $\begin{array}{l}38.9[23-72] \\
(\mathrm{DOD} \text { before CI1) } \\
28.9[6-61] \\
(\mathrm{DOD} \text { before CI2) }\end{array}$ & 1 year & $\begin{array}{l}46[13-83] \\
\text { months }\end{array}$ & $\begin{array}{l}\text { Average of: } \\
\text { CNC words in quiet }(n=\text { ?) } \\
\text { CUNY in quiet }(n=?) \text { and in noise }(n=?)\end{array}$ \\
\hline $\begin{array}{l}\text { Reeder et al., } \\
2014\end{array}$ & 21 & $\begin{array}{l}48.5(8.7) \\
{[36-74]} \\
\text { (age at CI1) } \\
53.8(8.0) \\
{[44-75]} \\
\text { (age at } \mathrm{CI} 2)\end{array}$ & $\begin{array}{l}16.8(14.6)[<1-45] \\
(\mathrm{DOD} \text { before CI1) } \\
21.4(16.8)[<1-55] \\
\text { (DOD before CI2) }\end{array}$ & $\begin{array}{l}1,3,6,9 \\
\text { and } 12 \\
\text { months }\end{array}$ & $5.2(4.6)[1-17]$ & $\begin{array}{l}\text { CNC words }(n=17-21) \\
\text { HINT sentences }(n=16)^{\mathrm{b}} \\
\text { TIMIT sentences in quiet and in noise } \\
(n=17-21) \\
\text { BKB-SIN test }(n=17-21) \\
\text { Localization }(n=17-21)\end{array}$ \\
\hline $\begin{array}{l}\text { Boisvert et al., } \\
2016\end{array}$ & 67 & $\begin{array}{l}62.6(10.1) \\
\text { (age at CI1) } \\
67.1(10.4) \\
{[50-87]} \\
\text { (age at CI2) }\end{array}$ & $\begin{array}{l}11.8(13.5) \\
\text { (DOD before CI1) } \\
12.5(14.2) \\
\text { (DOD before CI2) }\end{array}$ & 1 year & $4.5(4.6)$ & $\begin{array}{l}\text { CNC phoneme score for each individual } \\
\text { ear }(n=67) \\
\text { CNC phoneme score with } 2 \text { CIs }(n=40)\end{array}$ \\
\hline
\end{tabular}

Values are expressed as mean (SD) [range], unless otherwise indicated. DOD, duration of deafness; CNC, consonant-nucleus-consonant; HINT, hearingin-noise test; CUNY, City University of New York sentence test; OST, Oldenburger sentence test; BKB-SIN, Bamford-Kowal-Bench speech-in-noise test; TIMIT, database of sentences in different American dialects, joint effort between Texas Instruments (TI), the Massachusetts Institute of Technology (MIT) and the Stanford Research Institute; WRS, word recognition score; SRS, sentence recognition score.

a Data derived from graphs or tables.

${ }^{\mathrm{b}} \mathrm{CI} 2$ data at the 9-month interval were available for only 16 patients.

study of Boisvert et al. [2012], it was not clear if all 10 participants participated in each test. Reeder et al. [2014] also did not indicate how many participants performed each test.

Table 3 shows which preoperative factors were analyzed in each study and which factors had an effect on hearing performance. A factor could be correlated to the study outcome or be a predictor.

Predicting Sequential Cochlear Implantation Performance

\section{Discussion}

This systematic review summarizes which preoperative factors play a role in the prediction of sequential cochlear implantation performance according to the literature available to date. This knowledge can assist health care professionals to provide evidence-based advice when managing the expectations from a second CI. The includ- 


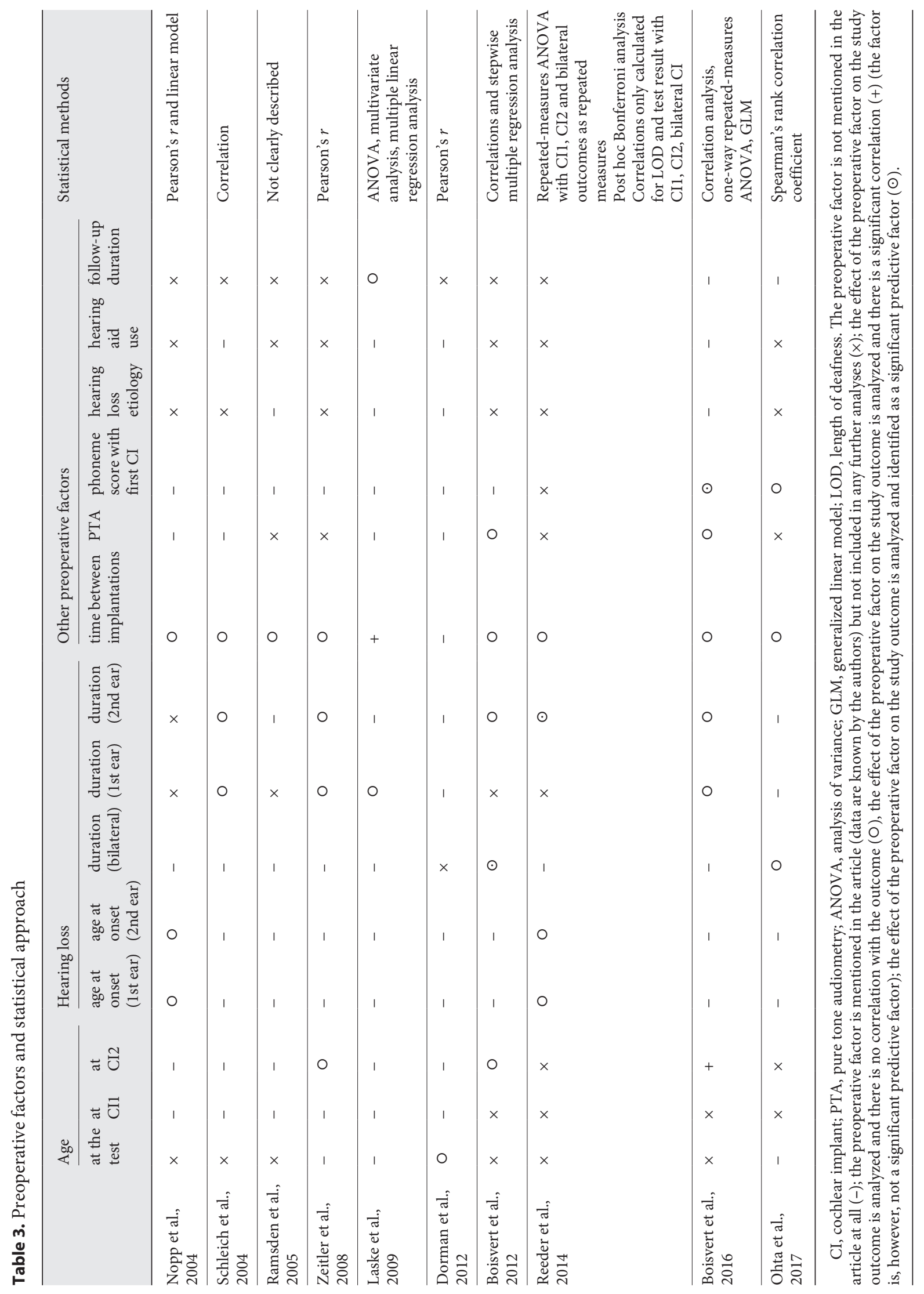


ed studies are, unfortunately, heterogeneous and predominately retrospective chart review studies, with level 3 evidence [Shekelle et al., 1999]. The goal of most studies was to examine the benefit of sequential bilateral implantation over unilateral implantation [Laske et al., 2009; Nopp et al., 2004; Ohta et al., 2017; Ramsden et al., 2005; Reeder et al., 2014; Schleich et al., 2004]. Whether or not certain prognostic factors influenced the study outcome was a secondary outcome in these studies. As displayed in Table 1, the prognostic factors of interest were inadequately defined in a number of studies. For example, while some studies defined "deafness" as severe-to-profound [Boisvert et al., 2012; Dorman et al., 2012; Laske et al., 2009; Ramsden et al., 2005; Reeder et al., 2014; Zeitler et al., 2008], Ohta et al. [2017] described it as an average of $\geq 110 \mathrm{~dB}$ HL and the remaining 3 papers provided no definition at all for deafness [Boisvert et al., 2016; Nopp et al., 2004; Schleich et al., 2004]. Due to the abovementioned issues, the pooling of data was not possible and drawing straightforward conclusions was challenging.

\section{Correlations and Predictors}

Several studies reported correlations between preoperative factors and the study outcome [Dorman et al., 2012; Nopp et al., 2004; Zeitler et al., 2008]. Correlation is a measure of association between two variables. The correlation coefficient $(r)$ tells how much one variable tends to change when the other one does, and when $r=0$, there is no relationship. When $r$ is positive, there is a trend that one variable increases as the other one does, and when $r$ is negative, there is a trend that one variable decreases as the other one does. To examine the strength between a possible predictive factor and outcome, or to create a prediction model, a stepwise multiple-regression analysis would be required. This is only possible when a study sample is large enough, because for each factor studied in such a regression analysis, a minimum of 10 patients is required.

Sequential cochlear implantation performance may be influenced by a long duration of deafness. Reeder et al. [2014] found that a prolonged duration of severe-to-profound deafness before the second cochlear implantation was a predictor for poor performance after sequential cochlear implantation with CI1, CI2, and both implants (consonant-nucleus-consonant [CNC] words, HINT in noise, TIMIT in noise, TIMIT in quiet, localization, and BKB-SIN with noise from the front). However, they noted that this effect could possibly be attributed to other time-based hearing history variables as they found a significant correlation between the duration of deafness in the second implanted ear on the one hand, and duration of deafness in the first implanted ear, age at the onset of severe-to-profound hearing loss, and time between surgeries on the other. Unfortunately, their sample size was not large enough to differentiate each time-based effect. Boisvert et al. [2012] showed that the duration of bilateral severe hearing loss was a predictor for sequential implantation outcome (speech recognition with CI1 and CI2). However, they based their conclusions on a study involving only 10 patients, who had been included in the study because they had a long-standing hearing loss before the first cochlear implantation (selection bias). No significant correlation between the duration of hearing loss and sequential cochlear implantation outcome was found in 5 other studies [Boisvert et al., 2016; Laske et al., 2009; Ohta et al., 2017; Schleich et al., 2004; Zeitler et al., 2008]. The current literature does not consistently measure and analyze all of the important time-based hearing history variables such as duration of deafness in each ear and both ears together, age at onset of hearing loss and implantation, and time between implantations. Therefore, robust conclusions cannot be made as to what effect the duration of severe-to-profound deafness has on the outcomes of sequential bilateral cochlear implantation.

Boisvert et al. [2016] showed that the most reliable predictor of phoneme recognition scores in quiet for the second $\mathrm{CI}$ and for bilateral CIs was the phoneme recognition score with the first CI. Ohta et al. [2017] did not find a significant correlation between word and sentence recognition scores in silence with the first and second CIs, but their study was less robust (Table 1). Although speech understanding with the first CI seems an important factor and is possibly the best predictor of sequential implantation performance, unfortunately, no other studies assessed its predictive value. In order to examine if speech understanding with the first $\mathrm{CI}$ is indeed a reliable predictor, more studies should be performed.

In the 4 studies that analyzed the effect of age, there was an agreement that advanced age at implantation did not lead to a reduced sequential implantation outcome [Boisvert et al., 2012, 2016; Dorman et al., 2012; Zeitler et al., 2008]. Boisvert et al. [2016] did find a negative correlation between age and phoneme recognition performance in quiet with CI1, CI2 and bilateral CIs, but concluded that it was not a predictor for poor outcome. The upper limit of the patients' ages in this review study was 87 years. Unfortunately, in 5 studies, the ages were reported but the authors did not describe the relationship between age and study outcome. While patients worldwide are getting older and cochlear implantation becomes 
available for an increasing amount of elderly patients, studying the effect of age will remain important.

The degree of hearing loss (pure tone average) before implantation had no influence on the phoneme recognition score with the second CI or with both CIs together according to Boisvert et al. [2016]. The study of Boisvert et al. [2012] reported no correlation between the pure tone average and the average speech reception score (SRS) with CI1 or CI2 (averaging the results of the City University of New York sentence test in quiet and in noise and $\mathrm{CNC}$ word lists).

The effect of the length of the interval between implantations was analyzed in all studies but one. Intervals varied between 1 month and 24.4 years, but did not affect sequential cochlear implantation performance in any of the studies [Boisvert et al., 2012, 2016; Laske et al., 2009; Nopp et al., 2004; Ohta et al., 2017; Ramsden et al., 2005; Reeder et al., 2014; Schleich et al., 2004; Zeitler et al., 2008]. For that reason, a long interval between implantations should not be considered a contraindication for sequential cochlear implantation. This is different from the pediatric population. Neurophysiological background studies have shown that implantation of both implants before the age of 3.5 years is important for binaural pathway development [Sharma et al., 2005]. In postlingually deafened adults, the binaural auditory system and auditory cortex are well developed and early second implantation seems less vital [Eggermont, 2008].

\section{Comparison with Literature on Predictive Factors in Unilateral Cochlear Implantation}

Several large studies have been published on the factors that may affect unilateral cochlear implantation performance. Duration of deafness and age at onset of hearing loss have consistently been reported as being inversely related to unilateral cochlear implantation outcome. [Blamey et al., 2013; Green et al., 2007; Holden et al., 2013; Leung et al., 2005; Rubinstein et al., 1999]. However, these correlations are not as apparent in studies on sequential bilateral implantation. It is possible that age at implantation and duration of deafness have an impact on the performance of the first CI, but as soon as the brain has adapted to the listening situation with one CI, those factors may no longer be important for the benefit of the second CI. The performance level with the first CI may be a more important predictor than other preoperative factors that played a role in unilateral implantation.

The literature has shown that there is no consensus on the effect of age at the time unilateral implantation. Some studies described poorer results for patients older than
60/65 years [Blamey et al., 2013; Friedland et al., 2010; Holden et al., 2013], but then others observed no difference in speech recognition scores between younger and older CI recipients [Budenz et al., 2011; Carlson et al., 2010]. Blamey et al. [2013] found that etiology was significantly related to speech recognition; meningitis patients had lower speech recognition while patients with Meniere's disease had higher speech recognition than patients with other etiologies. The effect of etiology on sequential bilateral implantation outcome has not yet been described in the literature.

\section{Clinical Relevance}

Prior to cochlear implantation, audiologists and otologists usually discuss what performance levels and outcomes a patient may expect. In their judgment, when considering which patients are suitable candidates for implantation, they take into account each patient's characteristics and medical and hearing history. Much has been written about the preoperative factors affecting unilateral cochlear implantation outcome, but literature on sequential bilateral implantation outcome is rather scarce. This systematic review shows that the success of sequential bilateral implantation performance does not depend on the same factors as in unilateral cochlear implantation. Based on the best evidence available to date, the factors advanced age, a long duration of deafness, or a long interval between implantations, do not necessarily lead to poor sequential cochlear implantation outcome. The level of performance of the first CI may be an important predictor for sequential implantation performance, but, to our knowledge, this has only been examined in 2 studies.

CI teams can use the current information to manage their patients' expectations. Importantly though, in order to offer patients accurate tailor-made advice, studies are needed that review the effect of all possible relevant preoperative factors and create a prediction model.

\section{Disclosure Statement}

The authors of this review study report no conflicts of interest.
Smulders/Hendriks/Eikelboom/ Stegeman/Santa Maria/Atlas/Friedland 


\section{References}

Blamey P, Artieres F, Baskent D, Bergeron F, Beynon A, Burke E, et al: Factors affecting auditory performance of postlinguistically deaf adults using cochlear implants: an update with 2,251 patients. Audiol Neurootol 2013; 18:36-47.

Boisvert I, McMahon CM, Dowell RC: Long-term monaural auditory deprivation and bilateral cochlear implants. Neuroreport 2012;23:195199.

Boisvert I, McMahon CM, Dowell RC: Speech recognition outcomes following bilateral cochlear implantation in adults aged over 50 years old. Int J Audiol 2016;55(suppl 2):S39S44.

Budenz CL, Cosetti MK, Coelho DH, Birenbaum B, Babb J, Waltzman SB, Roehm PC: The effects of cochlear implantation on speech perception in older adults. J Am Geriatr Soc 2011; 59:446-453.

-Carlson ML, Breen JT, Gifford RH, Driscoll CL, Neff BA, Beatty CW, Peterson AM, Olund AP: Cochlear implantation in the octogenarian and nonagenarian. Otol Neurotol 2010; 31:1343-1349.

Dorman M, Spahr A, Gifford RH, Cook S, Zhanga T, Loiselle L, Whittingham J, Schramm D: Bilateral and bimodal benefits as a function of age for adults fitted with a cochlear implant. J Hear Sci 2012;2:Ea37-Ea39.

Dounn CC, Tyler RS, Witt S, Ji H, Gantz BJ: Sequential bilateral cochlear implantation: speech perception and localization pre- and post-second cochlear implantation. Am J Audiol 2012;21:181-189.

Eggermont JJ: The role of sound in adult and developmental auditory cortical plasticity. Ear Hear 2008;29:819-829.

-Friedland DR, Runge-Samuelson C, Baig H, Jensen J: Case-control analysis of cochlear implant performance in elderly patients. Arch Otolaryngol Head Neck Surg 2010;136:432438.

-Green KM, Bhatt Y, Mawman DJ, O’Driscoll MP, Saeed SR, Ramsden RT, Green MW: Predictors of audiological outcome following cochlear implantation in adults. Cochlear Implants Int 2007;8:1-11.
Hayden JA, van der Windt DA, Cartwright JL, Cote P, Bombardier C: Assessing bias in studies of prognostic factors. Ann Intern Med 2013;158:280-286.

Holden LK, Finley CC, Firszt JB, Holden TA, Brenner C, Potts LG, Gotter BD, Vanderhoof SS, Mispagel K, Heydebrand G, Skinner MW: Factors affecting open-set word recognition in adults with cochlear implants. Ear Hear 2013;34:342-360.

Kraaijenga VJ, van Zon A, Smulders YE, Ramakers GG, Van Zanten GA, Stokroos RJ, Huinck WJ, Frijns JH, Free RH, Grolman W: Development of a squelch effect in adult patients after simultaneous bilateral cochlear implantation. Otol Neurotol 2016;37:1300-1306.

Laske RD, Veraguth D, Dillier N, Binkert A, Holzmann D, Huber AM: Subjective and objective results after bilateral cochlear implantation in adults. Otol Neurotol 2009;30:313318.

Laszig R, Aschendorff A, Stecker M, Müller-Deile J, Maune S, Dillier N, et al: Benefits of bilateral electrical stimulation with the nucleus cochlear implant in adults: 6-month postoperative results. Otol Neurotol 2004;25:958-968.

Leung J, Wang NY, Yeagle JD, Chinnici J, Bowditch S, Francis HW, Niparko JK: Predictive models for cochlear implantation in elderly candidates. Arch Otolaryngol Head Neck Surg 2005;131:1049-1054.

Litovsky R, Parkinson A, Arcaroli J, Sammeth C: Simultaneous bilateral cochlear implantation in adults: a multicenter clinical study. Ear Hear 2006;27:714-731.

Moher D, Liberati A, Tetzlaff J, Altman DG: Preferred reporting items for systematic reviews and meta-analyses: the PRISMA statement. PLoS Med 2009; 6:e1000097.

Müller J, Schon F, Helms J: Speech understanding in quiet and noise in bilateral users of the MED-EL COMBI 40/40+ cochlear implant system. Ear Hear 2002;23:198-206.

opp P, Schleich P, D’Haese P: Sound localization in bilateral users of MED-EL COMBI 40/40+ cochlear implants. Ear Hear 2004;25: 205-214.
Ohta Y, Kawano A, Kawaguchi S, Shirai K, Tsukahara K: Speech recognition in bilaterally cochlear implanted adults in Tokyo, Japan. Acta Otolaryngol 2017;137:837-841.

Ramsden R, Greenham P, O’Driscoll M, Mawman D, Proops D, Craddock L, et al: Evaluation of bilaterally implanted adult subjects with the nucleus 24 cochlear implant system. Otol Neurotol 2005;26:988-998.

Reeder RM, Firszt JB, Holden LK, Strube MJ: A longitudinal study in adults with sequential bilateral cochlear implants: time course for individual ear and bilateral performance. J Speech Lang Hear Res 2014;57:1108-1126.

Rubinstein JT, Parkinson WS, Tyler RS, Gantz BJ: Residual speech recognition and cochlear implant performance: effects of implantation criteria. Am J Otol 1999;20:445-452.

-Schleich P, Nopp P, D’Haese P: Head shadow, squelch, and summation effects in bilateral users of the MED-EL COMBI 40/40+ cochlear implant. Ear Hear 2004;25:197-204.

Sharma A, Dorman MF, Kral A: The influence of a sensitive period on central auditory development in children with unilateral and bilateral cochlear implants. Hear Res 2005;203: 134-143.

Shekelle PG, Woolf SH, Eccles M, Grimshaw J: Clinical guidelines: developing guidelines. BMJ 1999;318:593-596.

Tyler RS, Dunn CC, Witt SA, Noble WG: Speech perception and localization with adults with bilateral sequential cochlear implants. Ear Hear 2007;28:86s-90s.

-Van Deun L, van Wieringen A, Wouters J: Spatial speech perception benefits in young children with normal hearing and cochlear implants. Ear Hear 2010;31:702-713.

Verschuur CA, Lutman ME, Ramsden R, Greenham P, O’Driscoll M: Auditory localization abilities in bilateral cochlear implant recipients. Otol Neurotol 2005;26:965-971.

Zeitler DM, Kessler MA, Terushkin V, Roland TJ, Jr., Svirsky MA, Lalwani AK, Waltzman SB: Speech perception benefits of sequential bilateral cochlear implantation in children and adults: a retrospective analysis. Otol Neurotol 2008;29:314-325.
Predicting Sequential Cochlear Implantation Performance 